\title{
PROCESSOS NARRATIVOS NOS CONTOS DE MACHADO DE ASSIS
}

\author{
Ana Maria Lisboa de Mello
}

RESUMO: Cet essai présente quelques procédures narratives employées par Machado de Assis dans ses nouvelles, tels que les référents à l'instance et à la situation narrative, à la pratique de l' hypertextualité, au dialogue avec la tradition mythique et littéraire, en empruntant des chemins encore peu suivis dans le cadre de la création de l'auteur au niveau de la nouvelle.

PALAVRAS-CHAVE: conto, tradição, modernidade, narrador, oralidade, hipertextualidade.

$L^{\prime}$ oeuvre est tout ensemble une fermeture et un accès, un secret et la clé de son secret. Jean Rosset

Em seu livro Forme e signification, Jean Rosset demonstra, através das obras de escritores franceses, alguns muito distanciados quanto ao estilo e motivos trabalhados, como Corneille e Proust, que as estruturas da imaginação correspondem a estruturas formais, ou seja, "os mesmos princípios secretos que fundam e organizam a vida subjacente de uma criação organizam também a composição" (ROSSET, 1995, p.XV). Chama de "estruturas" as constantes formais empregadas por um autor, reveladas em associações, linhas de força, figuras obsedantes, ecos, convergências, cujos elos revelam um universo mental; cada artista reinventa essas estruturas segundo suas necessidades.

O reconhecimento de Machado de Assis como escritor advém da existência, em sua obra, de uma estreita integração e harmonia entre forma e significação. As estruturas da ficção machadiana ensejam rupturas com o passado literário, estabelecendo regras que obedecem às suas próprias lógicas. Ao dialogar com a tradição literária, Machado retoma e, simultaneamente, transforma aquilo que pode vir a serviço da significação que tenciona construir.

O conto machadiano não nasce de uma tradição brasileira, já que essa espécie

Ana Maria Lisboa de Mello é professora de Literatura Brasileira do Instituto de Letras da UFRGS. 
narrativa ainda não se firmara na nossa história literária quando, nos anos sessenta, do século XIX, o escritor começa a publicar os primeiros contos em jornais e revistas. Antes da publicação da reunião intitulada Contos fluminenses (1870), que reúne narrativas produzidas ao longo da década de 60 , destaca-se apenas o livro Noite na taverna, de Álvares de Azevedo, entre as manifestações do gênero no Brasil. Na visão de Alberto de Oliveira, citada por Herman Lima, é Machado de Assis quem dá um novo rumo à incipiente história do conto no referido século:

"Se nosso conto literário não começou com Machado de Assis (...) firmouse com ele, recebendo-lhe das mãos trato que nenhuma das outras anteriormente the haviam dado e feição nova e característica com o interesse dos temas e alinho e cuidado do estilo." (apud LIMA, 1986, p. 47)

$\mathrm{Na}$ sua produção contística, em torno de duzentos contos, Machado de Assis rompe com qualquer expectativa de enquadramento formal e estilístico. Sua escrita vale-se de uma gama tão variada de procedimentos que se torna refratária a qualquer tentativa de classificação ou filiação. Nesse sentido, seria legítimo chamá-lo de introdutor do que a crítica contemporânea chama de "conto moderno", em oposição ao "conto clássico", centrado na valorização do acontecimento, como em Poe e Maupassant, não fosse o fato de viver no Brasil, periferia em relação ao centro dos acontecimentos artísticos no séc. XIX. Como destaca Herman Lima, baseando-se em observação de Braga Montenegro, o brasileiro já pratica o conto quando Tchekhov ia publicando, com dificuldade de aceitação, os seus primeiros trabalhos em pequenos jornais moscovitas.(LIMA, 1967, p.24-26) Tchekhov edita sua primeira reunião de contos após 1884, quatorze anos depois da edição dos Contos fluminenses. No século XIX, tudo que se produz na Rússia é canalizado para Europa Central, sobretudo para Paris, fato que explica a difusão da obra de Tchekhov e outros escritores russos nesse centro cultural. Os intelectuais brasileiros contemplam de longe esse privilégio, como Machado, ou para lá se deslocam em busca de um contato mais direto com a efervescência cultural européia. Analisando os títulos da biblioteca pessoal de Machado de Assis, verifica-se que é composta por obras de autores franceses ou traduções, para o francês, da produção intelectual do ocidente (MASSA, 1961), de modo que ler em francês é condição fundamental para se estar a par dos acontecimentos no âmbito das artes e das ciências humanas.

A modernidade de Machado Assis como contista revela-se, primeiramente, na recusa a modelos preestabelecidos, de forma que tanto realiza contos que exploram o acontecimento, a exemplo de "A cartomante" $(\mathrm{VH})$, quanto produz narrativas que em nada se assemelham a esse formato, como "Missa do galo"(PR). Essas desenham atmosferas e impressões, que envolvem os protagonistas, sem que sobrevenha qual-

${ }^{1}$ Os contos citados são do volume II da Obra completa da José Aguilar, organizada por Afrânio Coutinho e editada em 1959. Após cada conto citado, indicaremos as iniciais do livro a que pertencem: CF (Contos Fluminenses); HM (Histórias da Meia-noite); Papéis avulsos (PA); HD (Histórias sem data); VH (Várias histórias); PR (Páginas Recolhidas); RCV (Relíquias da Casa Velha); OC (Outros Contos). Nem essa edição, nem a da Jackson contém os contos completos do autor, sendo que há alguns presentes na edição da José Aguilar que não estão na da Jackson e vice-versa. 
quer acontecimento para modificar o status quo. Mesmo quando trabalha o acontecimento, o autor tempera-o com uma dose de ironia que enfraquece o molde de ênfase na pura fábula, tal como no primeiro conto acima citado. Em outra direção, a variedade de histórias que narra vem acompanhada de uma diversidade de procedimentos discursivos que impossibilita responder a questão sobre como são construídos os contos machadianos, ainda que se buscasse uma síntese provisória. Ao se referir à feitura do conto, o autor expressa a sua opinião, salientando que se trata de um gênero difícil de realizar, apesar da enganadora facilidade:

"É um gênero difícil, a despeito da sua aparente facilidade e creio que essa mesma aparência de facilidade lhe faz mal, afastando-se dele os escritores e não lhe dando, penso eu, o público, toda a atenção de, muitas vezes, é credor." (ASSIS, apud LIMA, 1967, p. 24)

É próprio da modernidade machadiana a discussão, dentro do próprio conto, sobre a natureza da criação literária. Nesse sentido, critica o teatro romântico em "A chinela turca" (PA); discute a dificuldade da escrita, sobretudo a exposição dos sentimentos íntimos, em "O Cônego ou a metafísica do estilo"(VH); desmerece, através do riso, os excessos do gótico em "Um esqueleto"(OC). Ao mesmo tempo, lança mão de motivos e personagens da tradição mitológica, para retratar um ser humano que, embora tenha atravessado séculos professando fé e fraternidade, não consegue fugir de sua estreiteza moral e espiritual.

A variedade de procedimentos que emprega na elaboração de seus contos revela-se, primeiramente, no processo narrativo. Machado lança mão de narradores com diferentes perfis, ajustados às suas necessidades criativas. Ao escolher um narrador heterodiegético ${ }^{2}$ para relatar a história, como em "A segunda vida" (HD) e "Pai contra mãe" (RCV), entre outros, percebe-se que o grau de intrusão do narrador, em relação ao que narra, vai da discreta presença até a plena intrusão, caso em que a ironia se acentua.(GENETTE, Seuil,1972). Nos contos em que o narrador é protagonista da história que narra, relatando o que the aconteceu em algum momento do passado, como em "Missa do galo" (PR) e "Conto de escola"(VH), por exemplo, há uma ambigüidade muito acentuada no discurso do narrador. Esse entrelaça as visões do passado com as do presente, de maneira que, embora queira recuperar os acontecimentos, com os sentimentos experimentados, não consegue apagar a visão madura daquele que está distanciado do vivido, interferindo na recuperação pretendida. Machado de Assis recorre, também, ao narrador homodiegético, personagem secundária que dá sua versão dos acontecimentos e os avalia, sem o pleno conhecimento que a onisciência permite. É o caso do conto "Uma senhora" (HD) e "Um erradio" (PR). Um tipo especial de narrador-testemunha (ou homodiegético) surge em contos que já inicia com um diálogo entre duas personagens; nesse diálogo, uma narra a outra um caso testemunhado, tal como nos contos "Singular ocorrência" (HD) e "O anel de Polícrates" (PA).

${ }^{2}$ Obs: Utilizamos as denominações de Gérard Genette para designar os tipos de narradores, empregados por Machado de Assis. 
Nem sempre o uso do diálogo, eliminando a figura do narrador, funciona dessa maneira, ou seja, para ensejar um encontro em que uma das personagens narra à outra o que testemunhou sobre uma terceira. Há contos dialogados em que a matéria da conversa diz respeito, diretamente, aos protagonistas. É o caso do conto "Teoria do medalhão: diálogo" (PA), em que o pai discorre para o filho as maneiras e as vantagens de se tornar "medalhão". Machado faz aqui uma paródia dos ritos de passagens, em que o mais velho - "um sábio" - transmite ao jovem os seus conhecimentos, dando-lhe as condições para passar para outra etapa da vida. Ironicamente, às avessas da tradição, a "sabedoria" passada pelo pai é de como se estabelecer na sociedade, galgar postos e notoriedade, através do engodo e da falsa competência. $\mathrm{O}$ filho escuta passivamente as recomendações paternas, exercendo apenas a função de narratário no conto. A ironia empregada pelo pai, do início ao final de seu discurso, requer o distanciamento crítico do real, que o pai revela ter, mas não é recomendável, nem observável naqueles que assumem a carreira de "medalhão". Por isso, o pai recomenda ao filho: "Somente não deves empregar a ironia, esse movimento ao canto da boca, cheio de mistérios, inventado por algum grego da decadência, contraído por Luciano, transmitido a Swift e Voltaire, feição própria dos céticos e desabusados. Não. Usa antes a chalaça, a nossa boa chalaça amiga, gorducha, redonda, franca, sem biocos, nem véus...”.(ASSIS, 1959, p. 293)

Ao aludir ao ritual de passagem, entramos agora em outra questão do conto machadiano, que diz respeito à matéria narrada. Trata-se do aproveitamento que o autor faz da tradição mítica, antes referida. "Viver" é um conto dialogado que se vale dessa tradição, pondo em cena duas personagens - Prometeu e Ahasverus - para, ironicamente, desenhar a ambição de poder, inextirpável do homem, e o sonho de eternizar-se. Ahasverus é o legendário judeu errante que, por ter esbofeteado Jesus, foi condenado a errar pelo mundo até o Juízo Final (ROUART, apud BRUNEL,1994, p. 889). No diálogo com Prometeu, ele se mostra cansado da errância, desejando a morte libertadora, momento em que a personagem da mitologia grega lhe aponta a possibilidade de ser o Rei de uma nova "raça humana". O instinto de vida e a sedução do poder, como diria Adler, acabam por suplantar, em Ahasverus, o impulso de morte, tal como comentam as águias que, no alto de uma rocha, observam o diálogo das personagens:

"Uma águia. - Ai, ai, ai deste último homem, está morrendo e ainda sonha com a vida.

A outra. - Nem, ele a odiou tanto, senão porque a amava muito." (ASSIS, 1959, p.550)

Um contraponto ao motivo principal desse conto, está em "O imortal" (OC), publicado pela primeira vez em A estação, no qual o protagonista narra a seus amigos a história do pai, que possuía um frasco contendo uma espécie de "elixir da longa vida" dos alquimistas, mas, no relato, produto homeopático. A primeira metade lhe proporcionara mais de duzentos anos de vida e a segunda, que bebeu por opção, a almejada libertação via morte. Eis o narra o filho sobre os últimos dias do pai, que se 
cansou de contemplar o espetáculo da vida:

A alma de meu pai chegara a um grau de profunda melancolia. Nada o contentava; nem o sabor da glória, nem o sabor do perigo, nem o do amor. (...) Um dia, dizendo-lhe eu que não compreendia tamanha tristeza, quando eu daria a alma ao diabo para Ter a vida eterna, meu pai sorriu com uma tal expressão de superioridade, que me enterrou cem palmos abaixo do chão. Depois, respondeu que eu não sabia o que dizia; que a vida eterna afigurava-se-me excelente, justamente porque a minha era limitada e curta; em verdade, era o mais atroz dos suplícios. (ASSIS, 1959, p. 869)

No diálogo com a tradição e seus mitos, Machado de Assis apropria-se, também, de estruturas, motivos e linguagem das narrativas orais. O conto intitulado "O dicionário" (PR) é uma paródia dos contos folclóricos, tendo por núcleo da ação ou o seu motivo central a realização de concurso público, cuja vitória representa a obtenção da mão da princesa. Contudo, ao retomar o motivo tradicional, Machado mostra a fraude do rei (um demagogo que se alçou a essa condição) na condução do processo, possibilitando ao leitor que relacione as ações do conto à política brasileira. Outro conto que se insere nessa vertente da tradição oral é "Um apólogo" (VH). Neles, a agulha e a linha disputam o lugar de maior importância, cada uma reivindicando para si a primazia. A moralidade final explora o fato de que a linha é que vai à festa no corpo da baronesa, fato que o alfinete comenta para a agulha, observando que ela abria o caminho para outros fruírem a vida. Machado acrescenta, ao final, a fala de um excêntrico personagem - "um professor de melancolia" - para enunciar a moralidade do apólogo: "- Também eu tenho servido de agulha a muita linha ordinária!"(ASSIS, 1959, p. 538). Já o conto “Idéias de canário" (PR) (Idem, Ibidem, p. 589-593) apresenta uma estrutura muito comum em contos orais: aquela que apresenta personagens que passam por situações e provas similares, mas têm reações diferentes, reveladoras de seus caracteres. No conto machadiano, é a mesma personagem - o canário falante - que responde a mesma pergunta - "o que é o mundo?" - após viver experiências diferentes em espaços diversos. Com essa reiteração, modificadas as circunstâncias, o conto deixa implícita, como moralidade, a idéia de que a visão do mundo está presa às experiências da vida: quanto menores, mais estreita é a avaliação.(ASSIS,1959, p.589-93) No conto "Identidade"(OC), Machado coloca em foco o motivo dos sósias ou duplos no cenário do Egito antigo. Um faraó, chamado Pha-Nohr, cansado de governar e com ímpeto de conhecer o cotidiano dos homens, põe um sósia em seu lugar, um humilde escriba, e vai viver entre os homens comuns. Depois de muitos revezes, decide retornar e reassumir seu lugar de Faraó. Como era de se esperar, ao se apresentar diante do sósia e reivindicar seu lugar, o falso faraó declara que ele é "homem sedicioso" e um perigo para o Estado; na mesma hora, prende-o, julga-o e condena-o à morte.

É peculiar aos contos populares, como assinala Walter Benjamin, uma dimensão utilitária, visível no perfil do narrador: "seja num ensinamento moral, seja numa sugestão prática, seja num provérbio ou numa norma de vida - de qualquer 
maneira, o narrador é um homem que sabe dar conselhos" (BENJAMIN,1985,p.200). Esses conselhos, seguidamente, estão implícitos à história narrada. No caso do conto do faraó Pha-Nohr, mais de um ensinamento destila da história, entre os quais aquele que faz parte do adagiário brasileiro: "Se queres conhecer o vilão, mete-lhe o cargo na mão". O humilde escriba do início do conto, que não queria aceitar a função temporária de tomar o lugar do Faraó, revela-se um espertalhão no final.

Machado de Assis não explora somente os motivos e estruturas dos contos populares, como também a sua linguagem. Observando, com atenção, esse aspecto percebe-se que o autor emprega também a fala popular, necessária à caracterização das personagens e tipos que participam da história narrada. Isso é percebível, por exemplo, em "O alienista" (PA), visível no título do capítulo III, "Deus sabe o que faz". Expressões e ditados populares, que traduzem o saber do povo, comparecem em outros contos do autor, como veremos a seguir, fato que contraria a idéia de que Machado de Assis só utiliza a linguagem erudita e, ao mesmo tempo, coloca-o, também nesse aspecto, como precursor de procedimentos que serão empregados posteriormente na produção literária brasileira, sobretudo pelos modernistas.

Outro recurso que surge na contística de Machado, respondendo ao viés irônico de sua obra, é a prática da hipertextualidade, que se mostra como mais uma escolha inovadora dentro da produção brasileira, já que, em outras literaturas, como a francesa, esse tipo de relação entre textos comparece antes, como demonstra Genette em Palimpsestes. ${ }^{3}$ Para Genette, hipertexto é "todo texto derivado de um anterior por transformação simples (...) ou por transformação indireta"; nesse segundo caso, ele chama o procedimento de imitação, referindo-se à imitação de estilo. Entre as transformações, Genette inclui a paródia, o disfarce e a transposição, mantendo com o texto original uma relação lúdica, satírica ou séria, respectivamente. Entre as práticas da imitação de estilo, cita o pasticho, a charge (à maneira de...) e a invenção, também com intenção lúdica, satírica ou séria.(GENETTE, 1982, p.14) No conto intitulado "Na arca. Três capítulos inéditos do Gênesis"(PA), Machado usa, simultaneamente, os dois tipos de relações de natureza hipertextual identificadas por Genette: retoma uma passagem do Gênesis bíblico, conservando o estilo do hipotexto ( ou seja, fazendo um pasticho do texto original) e, ao mesmo tempo, transformando-o, ao inserir, como um enclave, três capítulos "inéditos" da Bíblia, no seu capítulo 8, em torno do versículo 12, quando Noé e sua família estão prestes a pisar em solo firme, depois de 40 dias navegando à deriva na Arca. Machado preserva a diç̧ão do discurso bíblico, transformando algumas imagens originais importantes, como "a arca flutuou na superfície das águas", que , no texto de Machado, passa a ser: "a arca boiava sobre as águas do abismo". Nos capítulos inseridos, os filhos de Noé lutam ferozmente pela partilha da terra onde, em seguida, irão aportar. Toda a terra do planeta é deles, mas

${ }^{3}$ Ao fazer a análise das relações transtextuais, entre as quais a hipertextualidade, Genette cita os autores franceses que, desde a Idade Média, produziram hipertextos. Cf. GENETTE, 1982. Apresentamos um resumo desses procedimentos hipertextuais, identificados pelo autor, no ensaio "A noção de hipertexto e sua contribuição para os estudos literários”. In: BITTENCOURT (Org.), 1996. p. 13-28 
isso não basta para conter o instinto de posse e de poder. A troca da expressão "superfície das águas" para "abismo das águas", no conto de Machado, alude ironicamente ao abismo da alma humana, reflexão implícita na última fala de Noé, no versículo 26, dos inéditos: "Eles ainda não possuem a terra e já estão brigando por causa dos limites. O que será quando vierem a Turquia e a Rússia?"(ASSIS, 1959, p.305). Aqui, Machado refere-se a um conflito internacional, contemporâneo a sua época, aproximando-o da luta dos filhos de Noé, emblemática da história da humanidade.

No conto "O sermão do diabo" (PR), Machado de Assis vale-se do mesmo procedimento ao recriar o Sermão da Montanha, capítulo 5 do "Evangelho segundo São Mateus", colocando o diabo como autor do discurso. O diabo, do alto do Corcovado, dirige-se aos seus discípulos, com uma dicção bíblica entremeada de ditos populares, incitando-os à prática do mal. Eis alguns excertos de seu discurso:

$1 .^{\circ}$ E vendo o Diabo a grande multidão do povo, subiu a um monte, por nome Corcovado, e, depois de se ter sentado, vieram a ele os seus discípulos.

2. ${ }^{\circ}$ E ele, abrindo a boca, ensinou dizendo as palavras seguintes:

4. ${ }^{\circ}$ Bem aventurados os afoutos, porque eles possuirão a terra.

....

$13 .^{\circ}$ Ouvistes que foi dito aos homens: Amai-vos uns aos outros. Pois eu digo-vos: Comei-vos uns aos outros; melhor é comer que ser comido; o lombo alheio é muito mais nutritivo que o próprio.

$22 .^{\circ}$ Não vos fies uns aos outros. Em verdade vos digo, que cada um de vós é capaz de comer seu vizinho, e boa cara não quer dizer bom negócio.

$23^{\circ}$ Vendei gato por lebre, e concessões ordinárias por excelentes, a fim de que a terra se não despovoe das lebres, nem as más condições pereçam nas vossas mãos.

$24 .^{\circ}$ Não quereis julgar para que não sejais julgado; não examineis os papéis do próximo para que ele não examine os vossos, e, e não resulte irem os dous para a cadeia, quando é melhor não ir nenhum. (ASSIS, 1959, p. 625-6)

Ainda, nessa linha, Machado de Assis produz contos que retomam a tradição literária, a exemplo de "A cena do cemitério"(PR), em que recria cena de Hamlet, de Shakespeare, ou, em processo de intertextualidade, alude a narrativas de outros autores, como faz no início do conto "Só!", em que ele introduz, sem dizer o título, um resumo do "O homem da multidão", de Poe. No conto de Poe, o "homem da multidão" enlouquece com a aglomeração urbana, decorrente da revolução industrial, enquanto, ironicamente, às avessas, o protagonista do conto machadiano corre o risco de enlouquecer com a solidão. Dessa maneira, o autor dialoga e recria a tradição, abrasileirando o tema, ao dar-lhe o toque de humor, tão ao gosto local.

Finalmente, cabe lembrar que, na variedade de procedimentos machadianos, destaca-se ainda a diversidade de situações narrativas. Em "Sereníssima República (Conferência do cônego Vargas)"( PA), por exemplo, o subtítulo do conto já indica 
em que situação Machado insere o discurso do narrador; "Ponto de vista" (HM) é um conto epistolar; a história em "A igreja do diabo"(HD) vem de velho um manuscrito beneditino; em "Trio em lá menor", o autor emprega os andamentos da música adagio cantabile, allegro ma non troppo; allegro appassionato, minueto - como títulos de capítulos, coadunando o ritmo musical ao da história de amor que narra. No tratamento das histórias, o escritor também faz uso de recursos da narrativa fantástica, mas procede como Gógol, desconstruindo o modelo pelo apelo ao humor e/ou ironia, a exemplo de "Uma excursão milagrosa" (OC), "Uma vista de Alcebíades. Carta do desembargador x...ao chefe da polícia da corte" (PA), "Entre santos" (VH).

Dentre outros que ainda estão por ser trabalhados, os pontos que levantamos a respeito do conto machadiano são aspectos que ainda não foram suficientemente vistos na obra do autor, sobretudo se considerarmos o fato de que, como assinalou Alberto de Oliveira, foi o escritor que consolidou o conto no Brasil, sendo paradigma para as gerações que o sucedem e o apontam como mestre do gênero, entre os quais Murilo Rubião e Lygia Fagundes Telles.

\section{BIBLIOGRAFIA}

ASSIS, Machado de. Obra completa. Org. por Afrânio Coutinho. Rio de Janeiro, José Aguilar, 1959. v.II

BENJAMIN, Walter. Obras escolhidas. São Paulo, Brasiliense, 1985. v. 1

BRUNEL, Pierre. (org.). Dictionnaire des mythes littéraires. Paris, Éditions du Rocher, 1994.

GENETTE, Gérard. Figures III. Paris, Seuil, 1972.

. Palimpsestes. La littérature au second degré. Paris, Seuil, 1982.

LIMA, Herman. Evolução do conto. In: COUTINHO, Afrânio (dir.). A literatura no Brasil. Rio de Janeiro, José Olympio/UFF, 1986.

. Variações sobre o conto. Rio de Janeiro, Tecnoprint, 1967.

MASSA, Jean-Michel. La bibliothèque de Machado de Assis. In: Revista do Livro. n. 21-22, mar.-jun, 1961.

PAULME, Denise. La mère dévorante Essai sur la morphologie des contes africains. Paris, Gallimard, 1976.

ROSSET, Jean. Forme et signification. Paris, José Corti, 1995.

TCHÉKHOV, Anton. Euvres. Paris, Gallimard, 1992. v. 3. (Bibliothèque de la Pléiade). 